\title{
A evolução do conhecimento sobre as hepatites virais na região amazônica: da epidemiologia e etiologia à prevenção
}

\author{
The evolution of knowledge about viral hepatitis in Amazon region: \\ from epidemiology and etiology to the prophilaxy
}

Gilberta Bensabath $^{1}$ e Manoel do Carmo Pereira Soares ${ }^{1}$

\begin{abstract}
RESUM0
Desde os anos cinqüenta uma doença similar a febre amarela, porém considerada como nova doença, ocorre em áreas dos vales dos Rios Juruá, Purus e Madeira. Temida pelos residentes locais pela alta letalidade, sendo clinicamente uma hepato-encefalopatia de evolução fulminante (média de 5 a 6 dias). Dos que apresentam manifestações neurológicas $90 \%$ evoluem a óbito. Adoença é popularmente conhecida como febre negra de Lábrea e pelos patologistas como hepatite de Lábrea pela histopatologia hepática mostrar o aspecto vacuolar dos hepatócitos, daí considerarem-na uma nova doença. Incide principalmente em crianças e adolescentes do sexo masculino. 0 achado do HBsAg e de marcadores de vírus da hepatite D no soro e fígado dos pacientes, levaram os pesquisadores a considerarem a febre negra de Lábrea como uma superinfecção ou coinfecção do HDV. Na falta de vacina específica contra o HDV, a vacinação contra hepatite B aplicada após o nascimento é a prevenção recomendada.
\end{abstract}

Palavras-chaves: Febre negra de Lábrea. Hepatite viral. Hepatite B.

\begin{abstract}
Since the 1950 years a disease similar to yellow fever but thought to be a new disease with unknown etiology has been described to health and researcher authorities. This disease occurs in Jurua, Purus and Madeira Rivers valleys. It'is feared by local people by its high lethality. It'is clinically a hepato-encephalopathy (Average survival time of 5-6 days) About $90 \%$ of sick people with typical symptoms go to death. The disease is popularly known as black fever of Lábrea and by pathologist as Lábrea hepatites after the city where the first cases were observed. The specifc histopatologic picture of vesicular degeneration of hepatocytes like spider cells motivate the local pathologist to think as a new disease: Lábrea hepatitis. The finding of HBsAg and marker of hepatites D vírus (HDV) in the serum motivate the researchers to think the disease as a superinfection of $\mathrm{HDV}$ in chronic carriers of $\mathrm{HBV}$. In absence of a specific vaccine against $\mathrm{HDV}$, the vaccine against $\mathrm{HBV}$, must be given soon after the birth is the recommended prevention.
\end{abstract}

Key-words: Black fever of Lábrea. Viral hepatitis. Hepatitis B.

Os estudos sobre as hepatites virais na Amazônia foram praticamente consequiência das pesquisas sobre arboviroses, em geral, e, da febre amarela, em particular. Estudos sobre esses vírus foram implantados em 1953, no Instituto Evandro Chagas (IEC), então fazendo parte da Fundação SESP/MS, em colaboração com a Fundação Rockfeller, núcleo este denominado Belém Virus Laboratory. Segundo Shope, os planejadores (Wilbur Downs e Max Theiller, entre outros), were just as bright and perspective in the1950's as those in the 1990 ' $\mathrm{s}^{29}$ quando anteciparam a descoberta de outros vírus, além da febre amarela e causadores de infecções que, só em 1992, ele, Shope em colaboração com outros pesquisadores, viriam chamar de emergentes. Embora tivessem em mente os arbovírus, os estudos ecoepidemiológicos sobre as arboviroses, abriram perspectivas para 0 conhecimento da nosologia de populações dispersas e em estreito contato com a biota do Trópico Úmido.

Conquanto haja referências, pelo menos em suas manifestações e conseqüências mais graves, da ocorrência das hepatite virais no vale do Madeira ${ }^{21}$, a rarefação demográfica, a ausência de cuidados ao binômio saúde-doença, a evolução do conhecimento das hepatites como infecções só a partir dos anos quarenta do século passado, uma abordagem científica

1. Instituto Evandro Chagas da Secretaria de Vigilância em Saúde do Ministério da Saúde, Belém, PA.

Endereço para correspondência: Dra.Gilberta Bensabath. Serviço de Epidemiologia/Instituto Evandro Chagas. Av. Almirante Barroso 492, Marco, 66090-000 Belém, PA.

Telefax: 91 211-4447.

e-mail: gilbertabensabath@ iec.pa.gov.br 
sistematizada e continuada das hepatopatias na Amazônia, só se viabilizou nas décadas seguintes. Os relatórios de Oswaldo Cruz, o de 1910, sobre as condições sanitárias do Rio Madeira, e 0 de 1913 sobre essas condições no valle do Amazonas, refletindo os motivos apontados acima, somados com a brevidade da permanência ${ }^{13}$, não faz referências a quadros clínicos correspondentes às diferentes manifestações do que, posteriormente passou a ser conhecido como conseqüência de infecções pelos vírus das hepatites.

Como acontece na maioria das novas doenças, 0 início dos estudos das hepatites virais, na Amazônia, giraram em torno das formas graves, principalmente as formas fulminantes com manifestações clínicas íctero-hemorrágicas e encefalopáticas, ou seja, a laicamente conhecida como febre negra de Lábrea e, pelos patologistas que primeiro a estudaram como hepatite de Lábrea.

As ações a seguir descritas são agrupadas por períodos durante os quais as atividades na área do Rio Purus têm como características uma permanência maior ou menor no local e diferentes aspectos técnicos.

\section{ATIVIDADES DESENVOLVIDAS DE 1950 A 1968. À PROCURA DE UM AGENTE ETIOLÓGICO}

0 primeiro deslocamento de uma equipe do IEC , com destino ao município de Lábrea tendo como objetivo coletar espécimes de pacientes com febre e icterícia para fins de exames laboratoriais, ocorreu em 1951. Na sede desse município, o então Serviço Especial de Saúde Pública ( SESP) instalara um posto de saúde com recursos para as atividades básicas de laboratório. A equipe permaneceu de 2 a 9 de abril, realizando um inquérito em 140 domicílios da área urbana sobre casos com icterícia e febre com resultados negativos, porém obtendo a informação de que em localidades distantes situadas nos rios Pauinim,
Memoriá e Aquiri, afluentes do rio Purus, ocorriam casos com vômitos e icterícia. Foram coletadas amostras de sangue para exames de malária, leptospirose e malária tendo os pesquisadores concluído que os casos ocorridos deviam ter sido exacerbação de malária.

Porém, é em 1953, por ocasião do inquérito soroepidemiológico inicial para 0 estudo das arboviroses na Amazônia, que as formas graves das hepatites virais da Amazônia são referidas como uma nova doença. Assim, ao fazer coleta de amostras de sangue na cidade de Lábrea, localizada ao sudoeste do Estado do Amazonas, ás margens do rio Purus, Ottis R. Causey, que seria 0 diretor do Laboratório de Vírus de Belém de 1954 a 1963, anotou que uma das coletas era proveniente de uma pessoa que havia se recuperado de uma doença similar à febre amarela, a qual julgava ser uma nova doença viral, pois amostras de fígado de casos similares que haviam morrido, foram negativas para 0 vírus amarílico (Figura 1).

Somente na década seguinte, com o enfoque nas arboviroses tem início estudos já dirigidos à procura de um agente causal da nova doença nos quais os inquéritos soroepidemiológicos e a participaçâo interdisciplinar contribuíram com informações de monta na definição do rumo das pesquisas.

As primeiras informações sobre a evolução clínica e a alta letalidade, acompanhadas de soros foram recebidas no IEC em maio de 1963. Estes soros foram coletados de residentes no seringal S. Luís de Cassianã, no município de Lábrea, por uma equipe de profissionais dos diversos serviços de saúde sediados em Manaus após um surto de uma doença hepática febril ${ }^{11}$. Esses espécimes foram enviados pelo Dr. Djalma Batista, fundador e, então, Diretor do Instituto Nacional de Pesquisas da Amazônia (INPA) e foram submetidos a testes sorológicos para a febre amarela, por fixação do complemento com resultados negativos. Expedições posteriores ao município de Lábrea, conduzidas e executadas pelo IEC, já a partir do ano seguinte, trouxeram mais subsídios sobre 0 surto de 1963 e foram estudados mais detidamente os surtos posteriores ${ }^{22}$.

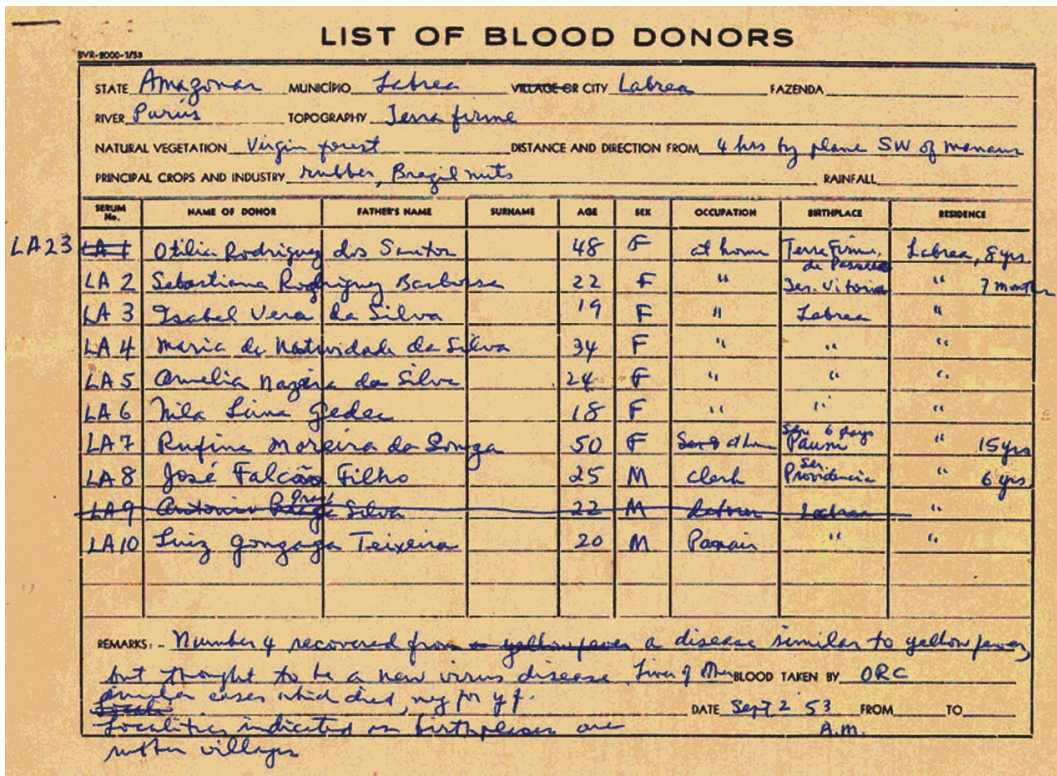

Figura 1 - Anotações de Causey sobre a nova doença. 
Pode-se considerar maio de 1964 com a ida de Shope e Bensabath à Lábrea 0 início das atividades sistematizadas do IEC com o objetivo de esclarecer a etiologia das hepatopatias da Amazônia Ocidental. A expedição, que contou com 0 auxílio do técnico Guilherme Brígido Nunes, foi motivada pela ocorrência de cinco óbitos de crianças, um nos meses de fevereiro e março e três em abril, do mesmo ano, na vizinhança da cidade de Lábrea, com a mesma sintomatologia dos casos ocorridos em 1963. Dos três óbitos ocorridos em abril de 1964, um da família Vitorino da Silva, que a época do óbito, 5 de abril de 1964, residia na ilha 23 de julho, município de Lábrea, onde faleceu e foi enterrado sem registro, não consta dos levantamentos feitos por Boshell ${ }^{11}$. As informações sobre a evolução da doença foram dadas pelo genitor, na sede do município de Lábrea, para onde, com sua família havia se mudado e constam do formulário preenchido no local pela autora deste.

Apesar de, durante a estadia do IEC, na área ( 14 a 17 de maio de 1964), não ter ocorrido nenhum caso fatal, irmãos dos casos ocorridos na ilha 23 de Julho e na Serraria (local defronte da cidade) foram encontrados com febre e icterícia e outras com febre somente.

Nesta ocasião, a equipe do IEC, auxiliada pelo Dr. Domingos da Silva Santos, médico da Diretoria Regional do Amazonas-FSESP e dos funcionários do posto de saúde, também da FSESP, profundos conhecedores da área e de sua população obteve as seguintes informações:

A população leiga denominava a entidade clínica ou talvez entidades clínicas em estudo febre ruim, febre de mau caráter, febre negra; posteriormente, outras denominações populares foram conhecidas; há atestados de óbitos assinados por médicos com 0 diagnóstico de hepatite infecciosa em 1957 e 1962; casos vem ocorrendo há vários anos em uma extensa área geográfica com uma distribuição irregular; na epidemia de 1963, pelo menos, 38 pessoas morreram, principalmente crianças ( estudo feito por Boshell em 196970 afirma ter ocorrido 24 óbitos no seringal São Luis de Cassianã; quando um membro da família sucumbia, comumente outros óbitos em irmãos também ocorriam dias, semanas ou até meses depois; maior prevalência em crianças e no sexo masculino; um caso típico durava de 2 a 8 dias antes do óbito e apresentava febre, dores abdominais, icterícia, vômitos escuros, agitação e confusão mental e coma pouco antes da morte, embora nem todos os casos mostrassem todas estas manifestações.

Uma família examinada nessa ocasião, 1964, relatou que sete crianças a ela pertencente, haviam falecido em 1963. Durante este surto foram obtidas cinco amostras de figado, que foram diagnosticadas como negativas para febre amarela ${ }^{11}$.

Nesta expedição a metodologia das atividades foi baseada na empregada no estudo das arboviroses: sangue dos pacientes com febre ou com febre e icterícia com menos de seis dias de início foram inoculados no local, em camundongos de menos de sete dias de idade, cobaio, e células BHK-21 e de rins de macaco verde; hemoscopia para plasmódio e leucocitometria e hematimetria foram efetuadas.
Próximo ao local onde ocorreram dois óbitos com suspeita da doença foram colocados quatro grupos de camundongos sentinela. Para estudos sorológicos foram coletadas 48 amostras de sangue, todos assintomáticos, dos quais 18 eram contatos familiares de casos fatais. Os animais e cultivos celulares inoculados foram mantidos sob inspeção durante toda a viagem de regresso a Belém, porém com resultados negativos. A hemoscopia de um desses pacientes, residente em um seringal, foi positiva para Plasmodium vivax.

Os estudos sorológicos tiveram como objetivo avaliar a prevalência de anticorpos para os arbovírus encontrados em humanos na região Amazônica (testes de inibição da hemaglutinação) e para estabelecer o diagnóstico diferencial com a febre amarela (testes de neutralização em camundongos e de fixação do complemento-FC) e com a febre hemorrágica boliviana, cujo agente etiológico é 0 vírus Machupo do gênero Arenavirus, grupo Tacaribe ( testes de FC utilizando como antígeno, cérebro de camundongo inoculado com 0 vírus Amapari, também do mesmo gênero e grupo do Machupo). Os resultados da soroprevalência de anticorpos contra os antígenos dos vírus dos grupos antigênicos A, B, C, Guamá, Bunyamwera e do Flebotomo, atuais gêneros Alfavirus, Flavivirus, Bunyavirus e Febovirus, mostraram resposta tanto do tipo primária como secundária para os vírus desses grupos, com predominância para o grupo Flavivirus, onde estão incluídos os vírus da febre amarela, Ilhéus, S. Luis, etc. A maior prevalência desse grupo foi devida a resposta à vacinação contra a febre amarela realizada no município após a epidemia de 1963, confirmado pelo encontro de $80 \%$ de anticorpos protetores para 0 vírus da febre amarela no teste de neutralização. Embora não tenha sido levantada a história de vacinação dessas crianças, a proporção de positividade de proteção, semelhante entre os com e os sem contatos com os casos fatais, resultados negativos por FCdos contatos sintomáticos para 0 vírus da febre amarela, dão suporte a afirmação que os resultados encontrados para esse vírus, foram induzidos pela vacinação antiamarílica. Quanto ao diagnóstico diferencial com um representante do grupo Tacaribe, o Amapari, foram encontrados resultados muito baixos, não superiores a 1:8, não havendo diferença entre os obtidos com os soros dos contatos sintomáticos e os assintomáticas examinadas e, portanto, foram inconclusivos ${ }^{11}$.

Em 1965, a ocorrência a partir de setembro, de casos fatais com a mesma sintomatologia, segundo informações transmitidas por missionários residentes em Lábrea , motivou 0 deslocamento de uma equipe do IEC ( Bensabath, Boshell e Pinheiro e 0 técnico Guilherme Brigido Nunes) para a sede do município, onde permaneceu de 17 a 21 de outubro. Neste local, a equipe foi informada que os casos estavam ocorrendo nos seringais de Santa Cruz do Paciá, 15 milhas rio abaixo, Miramar e Ilha das Onças, cinco milhas rio acima. 0 estudo deste surto mostrou dois aspectos logísticos que foram decisivos na evolução do conhecimento das hepatites virais na Amazônia: 0 estudo in loco no município de Lábrea de pacientes que desenvolveram manifestações clínicas diversas e 0 prosseguimento imediato em Belém, $\mathrm{PA}$, com a remoção para essa cidade no início de novembro, de uma família da 
qual já haviam morrido três irmãos dos quais dois já haviam sido examinados pela equipe em outubro. Dos cinco irmãos hospitalizados em Belém, um adoeceu com a mesma sintomatologia, vindo a morrer sete dias após a sua chegada. Estas observações permitiram obter as seguintes informações:

- confirmação do acometimento familiar. Nos relatórios e trabalhos publicados denominado microepidemias familiares $^{21123}$, atualmente, seria preferível denominá-los surtos, devido a sua localização restrita e envolvendo várias famílias. Das oito famílias residentes em Santa Cruz do Paciáa ${ }^{22}$, em quatro houve a ocorrência de oito óbitos, sendo quatro em uma só, no espaço de dois meses ( setembro a novembro);

- a incidência no mesmo período e local de casos graves e menos graves;

- caracterização clínica comprovada por laboratório: bilirrubina e aminotransferases elevadas e alterações do proteinograma e lipidograma todos indicativos de dano do parênquima hepático ${ }^{27}$;

- tentativas de isolamentos de agentes bacterianos e virais, pois, como foi possivel acompanhar e coletar espécimes de vários pacientes em diferentes fases evolutivas e de seus contatos familiares, foram realizadas para Salmonella, Ricketsia, Leptospira, Micobacteria e arbovírus, assim como para 0 diagnóstico sorológico para esses mesmos agentes, com resultados negativos, porém de extraordinária importância para o diagnóstico diferencial. Uma paciente com manifestações clínicas de dano hepático e que não foi ao óbito apresentou reação de Widal positiva, na fase aguda e que posteriormente foi verificado a presença da positividade em amostra de soro coletada anteriormente ao desenvolvimento dos sintomas clínicos o que faz supor que havia sido infetada por Salmonella Typhi antes, pois não foi obtido isolamento a partir de suas fezes coletadas na fase aguda e convalescente;

- achados histopatológicos do fígado de destruição parenquimatosa disseminada com infiltração periportal inflamatória do tipo mononuclear; a expressão células em mórula sinonímia das células em aranha de Madureira Pará foi bem caracterizada no ano seguinte ${ }^{24}$ pelos patologistas do IECe do INPA com a colaboração de outros patologistas do Pará e do Rio de Janeiro ${ }^{25}$.

- confirma sugestões formuladas em 1963 e $1964^{23}$ inclusive a expressa por Mario Moraes em 1963 quanto ao diagnóstico clínico: trata-se de uma hepatite viral, ficando a ser esclarecida a alta letalidade observada em crianças ${ }^{23}$.

Os estudos esparsos realizados em 1966, 1967 e 1968 apresentam algumas contribuições positivas e outras com resultados negativos.

Em 1966 teve inicio expedições a outras áreas além do município de Lábrea, tais como margens do rio Solimões, entre Manaus e a foz do rio Purus, e neste de sua foz até a localidade de Abufari e à cidade de Porto Velho, Território Federal de Rondônia, no rio Madeira, esta realizada em abril de 1966 pelos Drs. Jorge Boshell, F.P. Pinheiro e Leônidas B. Dias ${ }^{16}$. As expedições aos rios Solimões e Purus foram realizadas em dois períodos distintos: maio e junho de 1966 e de 9 de novembro de 1966 a 6 de fevereiro de 1967 por Boshell e 0 técnico Guilherme B. Nunes. Estas expedições tinham como objetivo coletar informações da ocorrência da doença em estudo. No rio Solimões a ocorrência parecia ser baixa. Em Porto Velho, a letalidade dos casos de hepatite hospitalizados era elevada, com maior incidência em adultos jovens ${ }^{15}$. A informação mais importante, obtida em conseqüência da similitude dos relatos e das expedições mais amplas, mencionadas acima, realizadas por Boshell e referida por ele: não há caso de febre negra na ausência de hepatite por vírus endêmica. Oscasos agudos, fatais parecem ser uma complicação da hepatite endêmica; os poucos casos que sobrevivem desenvolvem posteriormente um conjunto de sintomas semelhantes aos observados na convalescença dos casos de hepatite, e, posteriormente, uma tendência à cirrose $\mathrm{s}^{24}$.

Os estudos posteriores utilizando inquéritos soroepidemiológicos ${ }^{711} \mathrm{e}$ instalação de municípios sentinelas ${ }^{3}$ viriam confirmar e quantificar estas informações. Ainda neste ano (1967) e, em função do conhecimento vigente sobre a hepatite viral, são levantadas hipóteses sobre os possiveis fatores contribuintes a alta letalidade. Entre estes fatores foi sugerido em conseqüência das condições de vida e hábitos alimentares a ingestão da aflatoxina que poderia estar presente na castanhado-Pará e outros alimentos consumidos na região e possivelmente infectados pelo Aspergillus spp. Estudos sobre este aspecto foram efetuado nos anos seguintes com resultados negativos ${ }^{25}$.

Já em 1966 e 1967, foram divulgadas as observações histólogicas por Dias, de espécimes obtidos por necrópsia de casos de febre negra de Lábrea, que, então afirma: Repete-se a fisionomia histopatológica de necrose hepatocitária difusa, degeneração vacuolar dos hepatócitos com aspecto morular, hiperplasia Kupfferiana..... ${ }^{25}$ assinalando pela primeira vez 0 aspecto degenerativo, no qual se baseariam posteriormente para cunhar a expressão hepatite de Lábrea e sugerindo tratar-se de uma doença ainda desconhecida para a ciência ${ }^{15}$.

Também são desse ano, as tentativas de reprodução experimental da doença em primatas não humanos do Novo Mundo. Com este objetivo foram inoculados com amostras do fígado da paciente que morreu em Belém três exemplares de Saimiry scireus, um dos quais foi sacrificado aos 45 dias e outro aos 123 dias. 0 terceiro teve morte natural aos 190 dias. № animal sacrificado aos 45 dias 0 exame histológico do fígado mostrou células hepáticas polinucleadas, microvacuoladas, além de colestase e proliferação Kupfferiana. Embora não conclusivos, estes achados revelaram alterações hepáticas até então não observadas nos animais abatidos nas áreas silvestres enos mortos ou sacrificados após permanência prolongada nos biotérios ${ }^{25}$. Infelizmente estes experimentos não foram repetidos, devido à espera de melhores condições de trabalho com primatas não humanos.

As atividades realizadas em 1967 tiveram as seguintes características: participação também, de pesquisadores estranhos ao IEC, quer como consultores quer como colaboradores e, 0 início dos estudos de analise quantitativa da aflatoxina em alimentos por cromatografia em coluna de silicagel com 0 contrato de uma química com experiência em análise quantitativa de aflatoxina. Na implantação dessa 
tecnologia, teve importância as hipóteses já referidas acima sobre a contribuição de possíveis micotoxinas ingeridas na alimentação, apoiada pelo diagnóstico dado aos exames histológicos de três amostras de fígado de casos ocorridos em 1965, 1966 e 1967. Estes espécimes foram enviados por Boshell para 0 Dr. Donald Svoboda, Professor Assistente de Patologia do Centro Médico da Universidade de Kansas que distribuiu lâminas deste material para Hans Popper, Edward A. Gall e Gerrit Bras. 0 consenso de opinião é que as mudanças patológicas naqueles fígados não eram compatíveis com 0 diagnóstico de hepatite por vírus. As lesões sugeriam preferivelmente 0 envolvimento de um agente tóxico ${ }^{25}{ }^{26}$. Klatskin, da Universidade de Yale ao examinar anteriormente este material sugeriu microepidemia da doença de Reye.

Contribuição ainda deste ano 1967, porém só publicado em 1970 após aula dada por Pinheiro na Escola Nacional de Saúde Pública foi a descrição de surtos de febre negra da área rural do município Boca do Acre.

A descrição dos aspectos clínicos e epidemiológicos do surto pelo médico que os acompanhou, é considerado de relevância pois foi mostrado que na localidade onde ele ocorreu, Praia do Inferno, a letalidade era estatisticamente significante mais elevada que a observada em outras localidades do mesmo município. Também confirmou os achados de Boshell da ocorrência da febre negra fora de Lábrea, e os de outros pesquisadores quanto ao acometimento familiar, demonstrando em um fluxograma as relações de contato familiar com 0 aparecimento de novos casos ${ }^{12}$.

No ano seguinte (1968) um laboratório de cromatografia foi instalado no IEC, providenciada a obtenção de padrões frescos de aflatoxina e de conhecimentos das condições em que a produção da toxina se desenvolve. 0 primeiro alimento estudado foi a farinha de mandioca, por ser de mais provável contaminação devido nesta região, ter que ser estocada por longos períodos. Também foi levada em consideração a castanha (Bertholetia excelsa) por ter sido condenada a sua entrada nos Estados Unidos pelo Food and Drug Administration, sob o fundamento de contaminação de aflatoxina acima do compatível com a saúde humana. Estas atividades foram continuadas no ano seguinte com resultados da contaminação da farinha pela aflatoxina, contraditórios.

Ainda em 1968 foram elaborados projetos para a obtenção de recursos financeiros com a finalidade de obter uma lancha para viabilizar os estudos em toda a área do Purus, uma vez que Boshell fez três tentativas com muito poucos resultados, utilizando transportes federal, municipal e particular que tinham outras finalidades.

\section{9 - 1970: INQUÉRITO NA ÁREA RURAL DA AMAZÔNIA}

Nesse biênio, com exceção da abordagem equivocada em relação a aflatoxina e outras possíveis micotoxinas, as outra atividades foram decisivas na implantação no IEC de tecnologia adequada ao estudo das hepatites virais e, com 0 auxilio de outros pesquisadores o esclarecimento da etiologia da febre negra de Lábrea.
Os recursos foram finalmente conseguidos mediante convênio da Superintendência de Desenvolvimento da Amazônia (SUDAM) com a FSESP e a lancha batizada Orlando Costa fez sua viagem inaugural em torno de Belém, a 24 de setembro de 1969.

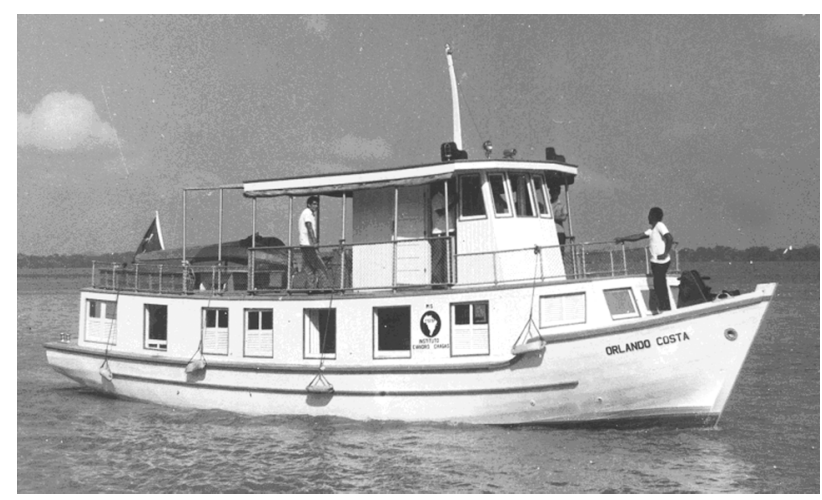

Figura 2 - Lancha Orlando Costa utilizada como meio de locomoção para as atividades de pesquisa entre 1969 a 1978.

Assegurado transporte próprio, no âmbito da epidemiologia, foi realizado por Boshell tendo como auxiliar o técnico Guilherme Brígido Nunes, um amplo estudo que incluiu o levantamento dos casos ocorridos em parte da bacia do rio Purus e alguns de seus afluentes e a coleta de amostras de sangue que possibilitou 0 primeiro inquérito soro epidemiológico realizado na Amazônia sobre um marcador do vírus da hepatite B ( $\mathrm{HBV}$ ), àquela altura denominado Antígeno Austrália ${ }^{7}$; a descrição clínica e epidemiológica de um surto em Boca do Acre $^{11}$ e, a detecção do Antígeno Austrália (AuAg) nos casos e contatos familiares ${ }^{7}$ das formas fulminantes.

Assim a lancha Orlando Costa saiu de Belém a 26 de setembro de 1969, retornando em junho de 1970, tendo como tripulação, pessoal da FSESP e gastos de manutenção subvencionados pela Fundação Rockfeller. Na impossibilidade de cobrir o universo do Purus resolveu-se escolher parte desse universo considerada como representativa para ser estudada de maneira mais pormenorizada, com censo de famílias, incidência e letalidade. 0 trecho escolhido foi da foz do rio Tapauá até a vila de Terruã, atual sede do município de Pauini, com uma extensão de 850 quilômetros, denominado por Boshell de Zona I. Outra zona (II) de estudos foi a que se estende da foz do Purus à do Tapauá, uma parte e da vila de Terruã até Boca do Acre (Amazonas) e cidades de Rio Branco e de Sena Madureira (Acre) por outra parte ${ }^{11}$.

Dada a grande extensão dessa área 0 estudo se limitou a história de certos surtos em localidades onde havia boa qualidade de informação. Também foi trabalhada uma terceira zona designada P constituída de afluentes, igarapés e lagos, ecologicamente diferentes das margens do Purus. Acomposição da água é diferente, desprovida de minerais, com baixa de $\mathrm{pH}$, carecendo de plankton ${ }^{11}$.

Na ausência de informações escritas, devido a falta de presença do Estado a metodologia seguida foi o depoimento, algumas vezes testemunhal, outras vezes, a força da tragédia 


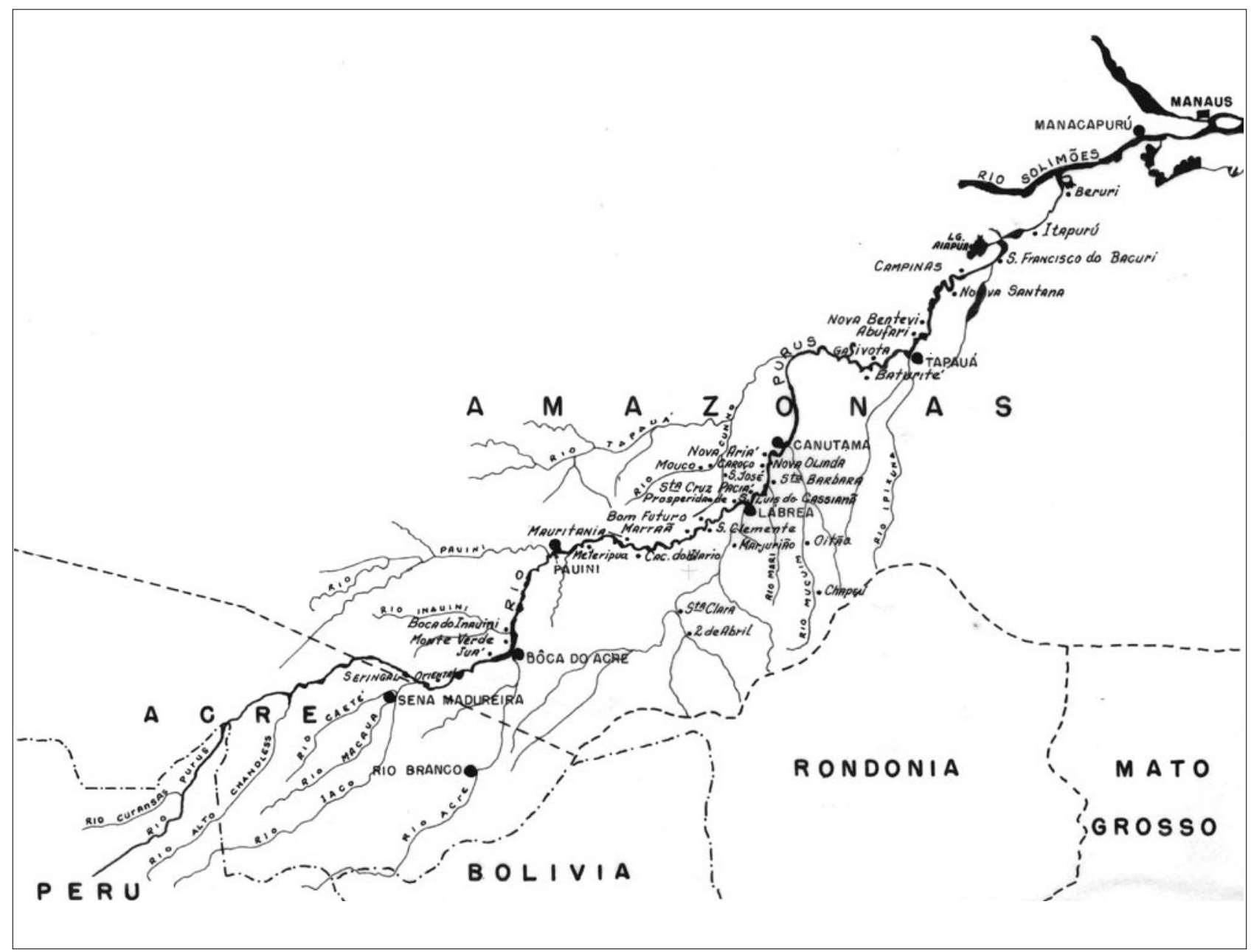

Figura 3 - Febre Negra de Lábrea . Expedição Dr. J. Boshell. Localidades visitadas de 1969 a 1970. Instituto Evandro Chagas - Fundação Serviços de Saúde Pủblica - Ministério da Saúde.

dando ensejo a dispersão das informações, provoca 0 relato dos acontecimentos por informantes distantes e que pela repetição permite a correção das distorções e lhes confere 0 selo da autenticidade. Assim foi realizado o levantamento dos casos graves e dos moderados concomitantes mesmo na ausência de profissionais ligados à saúde, pois como relata Boshell aquela altura:

A febre negra e seus sintomas são bem conhecidos pelos habitantes do Purus, os quais vivem permanentemente conscientes do perigo e ao acesso das primeiras manifestações. Estas são a febrezinha, a febre lenta, a febre baixa ou ainda a febre sem frio. Fazem a distinção com a bem conhecida malária, a qual não lhes causa temor. 0 segundo sintoma objetivo é a cor da urina, que é imediatamente reparada; expressões como urina escura, urina vermelha, urina que mancha a roupa, urina safroa, sintoma precoce que aparece geralmente com a inapetência, fadiga e enjôo. A icterícia, não escapa a observação e é recordada uma vez que dura muitos dias para limpar ${ }^{11}$. É evidente que com esta metodologia há vários fatores que prejudica a recoleta de dados, entre os quais a falha de memória que são mais freqüentes à medida que se trata de fatos mais remotos e, foi o motivo para considerar a estatística somente nos últimos sete anos (Tabela 1). Na zona I foi feito um censo de todos os habitantes e, em todas as localidades foram coletadas amostras de sangue para estudos sorológicos, não tendo sido observado uma proporcionalidade entre o número de residentes e as amostras de sangue coletadas.

Consideramos essa expedição um marco pelos seguintes motivos e resultados:

- a extensão da área de estudos;

- a incidência da enfermidade não está limitada a épocas determinadas e se observa durante todo 0 ano. Todavia, nos últimos sete anos houve maior incidência nos meses de junho e setembro;

- confirma os achados anteriores:maior letalidade abaixo dos seis anos e no sexo masculino.

- coeficientes de mortalidade específico e de letalidade muito elevados, embora este último esteja prejudicado pela falta de conhecimento dos casos mais leves e a falta de documentação.

Como conseqüência dessas atividades ou dando prosseguimento a elas, a introdução no IEC, da sorologia para o Antígeno Austrália ( $\mathrm{Au}$ ) e seu anticorpo propiciaram a indicação dos novos e definitivos rumos dos estudos, não só da febre negra, como também, de todas as hepatites virais, na Amazônia9?. 
Tabela 1 - Febre negra - Distribuição dos casos por grupo etário, sexo e área de estudo.

\begin{tabular}{|c|c|c|c|c|c|c|c|c|c|c|c|c|}
\hline & \multicolumn{12}{|c|}{ Casos fatais $=296$} \\
\hline & +18 & $\%$ & M & $\%$ & $\mathrm{~F}$ & $\%$ & -18 & $\%$ & $\mathrm{M}$ & $\%$ & $\mathrm{~F}$ & $\%$ \\
\hline Zona I & 32 & 18,4 & 23 & 71,9 & 9 & 28,1 & 142 & 81,6 & 99 & 69,7 & 43 & 30,3 \\
\hline Zona II & 12 & 15,2 & 7 & 64,3 & 5 & 35,7 & 78 & 84,8 & 52 & 66,7 & 26 & 33,3 \\
\hline Zona P & 7 & 23,3 & 6 & 85,7 & 1 & 14,3 & 23 & 76,7 & 13 & 56,5 & 10 & 43,5 \\
\hline Total & 53 & 17,9 & 36 & 71,7 & 15 & 28,3 & 243 & 82,1 & 164 & 67,5 & 79 & 32,5 \\
\hline
\end{tabular}

\begin{tabular}{lrrrrrrrrrrrr}
\multicolumn{110}{c}{ Casos não fatais = 400 } \\
\hline & +18 & $\%$ & M & $\%$ & F & $\%$ & -18 & $\%$ & M & $\%$ & F & $\%$ \\
\hline Zona I & 45 & 20,2 & 23 & 51,1 & 22 & 48,9 & 178 & 79,8 & 115 & 64,6 & 63 & 35,4 \\
Zona II & 33 & 29,2 & 20 & 60,6 & 13 & 39,4 & 80 & 70,8 & 52 & 65,0 & 28 & 35,0 \\
Zona P & 15 & 23,4 & 9 & 60,0 & 6 & 40,0 & 49 & 76,6 & 24 & 49,0 & 25 & 51,0 \\
\hline Total & 93 & 23,3 & 52 & 55,9 & 41 & 41,1 & 307 & 76,7 & 191 & 62,2 & 116 & 37,8 \\
\hline
\end{tabular}

\begin{tabular}{lrrr}
\hline & № de casos & Fatais & $\%$ \\
\hline Zona I & 397 & 174 & 43.8 \\
Zona II & 205 & 92 & 44.9 \\
Zona P & 94 & 30 & 31.9 \\
\hline Total & 696 & 296 & 42.5 \\
\hline
\end{tabular}

A associação desse antígeno com as hepatites virais foi demonstrada em $1967^{10}$ e posteriormente sua identificação como antígeno de superfície do vírus da hepatite B ( $\mathrm{HBsAg}$ ), só viria a ocorrer em 1970, e, os primeiros testes para a detecção do Au no soro já estavam disponíveis praticamente concomitante com a identificação do Au como parte da estrutura do vírus da hepatite B. A inclusão dessa sorologia nos estudos das hepatites virais na Amazônia, também foi praticamente concomitante.

Assim, em 1970, foram enviadas 68 amostras de soro, por Boshell, para McCollum do Departamento de Epidemiologia e Saúde Pública da Escola Médica da Universidade de Yale, Estados Unidos da América, para serem examinados pelas técnicas então disponíveis, para a detecção do mencionado antígeno. Desta amostra, faziam parte soros de casos fatais de 1965, de Santa Cruz do Paciá, sendo coletado da mesma pessoa amostras de soro, 20 dias antes de adoecer e 9 dias antes de morrer; dos casos que foram trazidos para Belém, tanto na fase aguda como na convalescente e de contatos familiares assintomáticos. Com a positividade em todos os soros da fase aguda, incluindo os fatais ${ }^{11}$, foi decidido que uma amostra mais ampla deveria ser examinada e a técnica deveria ser implantada no IEC. Com 0 objetivo, além de outros, de estudar a soroprevalência do antígeno Au e seu respectivo anticorpo, Boshell e sua equipe coletaram durante a expedição de 1969/70 já referida, 511 amostras de soros das quais 506 foram examinados, pelos primeiros testes desenvolvidos para a detecção do antígeno Au. testes estes, imunodifusão (ID), fixação do complemento (FC) e imunoeletrosmoforese(IEOP) considerados de baixa sensibilidade, especialmente em relação ao anticorpo. Estes testes foram executados no Laboratório de Hepatite da Universidade de YALE, New Haven, USA em outubro e novembro de 1970 pela autora deste artigo, sob a orientação de R. McCollum. Para a análise de soroprevalência do antígeno Au segundo as variáveis estudadas, foram utilizados os resultados obtidos por ID?7.

Nesta amostra, não foram incluídos soros de pacientes com febre de Lábrea, porém cerca de 31\% tinham história de icterícia. Considerando, ainda que os conhecimentos sobre a relação do antígeno do Au com 0 vírus da hepatite B eram ainda incipientes, esses estudos foram levados ao conhecimento da comunidade científica brasileira em 1971 ( VI Congresso Brasileiro de Medicina Tropical, realizado em Manaus), e que documentaram a presença do HBsAg em 31,6 \%, nos casos agudos com menos de um mês de início de sintomas, na microrregião do Purus ${ }^{211} \mathrm{e}$ 3,1\% em escolares assintomáticos residentes na cidade de Lábrea.

Ficou então implantado o conceito de que a febre negra de Lábrea fazia parte das hepatites virais e que somente 0 desenvolvimento do conhecimento sobre este grupo de doenças ajudaria a esclarecer a sua etiologia o que só viria a ocorrer na década seguinte.

\section{1 - 1975: IMPLANTACÃO DO DIAGNÓSTICO SOROLÓGICO DAS HEPATITES POR VÍRUS NO IEC, A VIGILÂNCIA EM ALTAMIRA, PARÁE OS INQUÉRITOSSOROEPIDEMIOLÓGICOS EM VÁRIAS ÁREAS DA AMAZÔNIA}

Adecisão de implantar imediatamente no IEC a tecnologia acima referida, usada na YALE, e a introdução dos aperfeiçoamentos posteriores desenvolvidos nos países industrializados, à medida do conhecimento de sua existência, foram decisivos para a continuação dos estudos da febre negra de Lábrea, em particular, e dos diversos tipos de hepatites, em geral, principalmente os etiológicos, permitindo a execução de extensos inquéritos em várias áreas da Amazônia ${ }^{6}$ (Tabela 2).

Os primeiros reagentes utilizados, tanto em ID como em IEOP, que foram técnicas introduzidas no IEC, eram de origem humana. Na ID, seguindo a mesma técnica usada por Blumberg, a de Ouchterlony ( testes de dupla difusão radial), em gel ${ }^{14}$, técnica hoje obsoleta, mas que na ocasião foi de extrema utilidade, pois, apesar de suas inconveniências, permitia 
Tabela 2 - Prevalência do HBsAgno soro de portadores sãos em algumas localidades da Amazônia segundo a residência por município, ano e os métodos empregados na detecção.

\begin{tabular}{|c|c|c|c|c|c|c|c|}
\hline \multirow[b]{3}{*}{ Município } & \multirow{3}{*}{$\begin{array}{c}\text { Data da coleta } \\
\text { do sangue passiva }\end{array}$} & \multicolumn{6}{|c|}{ Técnicas de laboratório } \\
\hline & & \multicolumn{2}{|c|}{$\begin{array}{l}\text { hemaglutinação passiva } \\
\text { reversa }\end{array}$} & \multicolumn{2}{|c|}{$\begin{array}{l}\text { contraimunoeletroforese } \\
\text { e imunodifusão }\end{array}$} & \multicolumn{2}{|c|}{ ELSA } \\
\hline & & $\mathrm{n}^{0}$ examinados & $\%$ HBsAg pos. & $\mathrm{n}$ - examinados & $\%$ HBsAg pos. & ㄲọ examinados & $\%$ HBsAg pos. \\
\hline Belém(PA) (militares e escolares) & 1971 & . & - & 535 & 0,7 & - & \\
\hline Itaituba(PA) (população em geral) & 1972 & . & . & 579 & 4,7 & - & \\
\hline Santarém(PA) (colonos e agricultores) & 1973 & . & . & 691 & 2,2 & . & \\
\hline Altamira(PA) (população em geral) & 1973 & . & . & 2.912 & 2,7 & . & \\
\hline Humboldt (MT) (população em geral) & 1974-1975 & . & - & 240 & 8,3 & - & \\
\hline Belém(PA) (doadores de sangue) & 1976-1978 & 1.192 & 1.5 & 4.152 & 1,0 & - & \\
\hline São Gabriel (AM) (Índios) & 1976 & $\cdot$ & $\cdot$ & 397 & 3,0 & - & \\
\hline Roraima(RO) (Índios) & 1976 & - & - & 211 & 3,3 & - & - \\
\hline Sena Madureira (AC) (residentes de 3 bairros) & 1976 & 236 & 13.4 & 239 & 9,2 & - & . \\
\hline Boca do Acre (AM) área urbana (população em geral) & 1979 & - & - & 448 & 4,6 & 448 & 6.9 \\
\hline Boca do Acre (AM) área rural (população em geral) & 1979 & - & - & 444 & 3,1 & 444 & 4.7 \\
\hline Conceição do Araguaia (garimpeiros do Cumaru (PA) & 1981 & 263 & 5.0 & 263 & 3,9 & 263 & 7.2 \\
\hline Total & & 1.694 & 3.6 & 11.433 & - & 1.155 & \\
\hline
\end{tabular}

reconhecer a identidade dos reagentes analisados frente a um antígeno ou anticorpo. Alíquotas dos reagentes utilizados no laboratório de hepatite do Departamento de Epidemiologia da Universidade de YALE foram trazidos para Belém, onde em janeiro de 1971 foi iniciado nos hospitais levantamento de pacientes que haviam recebido múltiplas transfusões de sangue. As 47 amostras coletadas foram examinadas com os reagentes trazidos da YALE de maneira que pudesse ser evidenciada uma perfeita identidade. Os soros positivos foram retestados em diluições em dobro e os que deram maior titulo foram escolhidos como reagentes passando a serem usados, para grande número de testes, segundo as recomendações adotadas na universidade mencionada anteriormente (Figura 4).

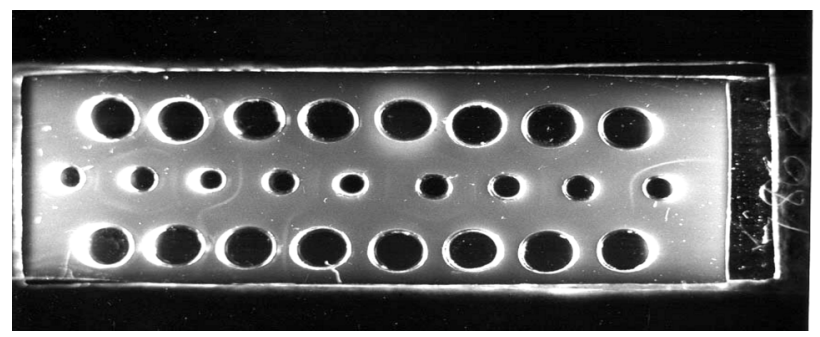

Figura 4 - Testes de Imunodifusão com controles no centro.

Antes do término do primeiro semestre de 1971, a ID concomitante com 0 IEOP já era utilizada nos levantamentos epidemiológicos, em 535 pessoas assintomáticas residentes em Belém ${ }^{9}$. 0 IEOP usado no diagnóstico do antígeno ( AuAg) e seu anticorpo (AuAb) , foi desenvolvido por Prince, com a finalidade de usá-lo nos bancos de sangue, pois tinha como vantagem a rapidez na execução dos testes Em 1972, reagentes para a detecção do HBsAg, obtidos em animais, fornecidos por laboratório comercial já estavam em uso no IEC.

As atividades deste período, pertinentes ao IEC, caracterizaramse por incluírem testes de Patologia Clínica, os de função hepática inclusive, também nas atividades de campo e, se estenderem a outras áreas da Amazônia com a instalação do primeiro município sentinela para vigilância das hepatites virais em Altamira, Pará,em 1973 .

Pelo IEC, na microrregião do Purus, foi realizada apenas uma expedição ao município de Lábrea, no período de 26 de julho a 4 de agosto de 1971, por motivo de dois óbitos de pacientes com sintomas compatíveis com febre negra de Lábrea. Há, pela primeira vez um levantamento de hemoscopia para malária e tentativas de isolamento de arbovírus de pacientes com apenas febre e sem alteração das aminotransferases.

Em 1973, é instalada em Altamira, Pará, a primeira área sentinela de vigilância das hepatites virais, com base no ambulatório e hospital da FSESP, único recurso de atenção médica então existentes na sede daquele município. Os dados clínicos, associados as provas de função hepática e de outros exames de análise clínicas, inclusive hemoscopia para Plasmodium sp que auxiliavam no diagnóstico diferencial, permitiam com razoável segurança firmar o diagnóstico clínico de hepatite viral, confirmado pelo teste sorológico para o HBsAg que, quando positivo, como hepatite $B(\mathrm{HB})$ e, quando negativo como hepatite não B (HNB). Estes estudos realizados em duas etapas em situações sócioeconômicas diferentes, a primeira no período de 1973 a 1976 e a segunda de 1980 a 1982 permitiram estabelecer coeficientes de morbidade para a população tanto da área urbana como rural, dados estes de difícil obtenção, para a área rural no Brasil, mesmo na primeira década do século XXI. A prevalência do HBsAg em 2912 portadores assintomáticos, residentes na área e rural, nesse período foi de 2,7\% ${ }^{9}$.

Ainda neste período, especificamente em 1974, é realizada a primeira investigação epidemiológica em torno de dois surtos consecutivos por diferentes tipos de vírus de hepatites, em Ananindeua, município componente da área metropolitana de Belém, em uma comunidade fechada, com alto padrão de condições de saneamento, em um grupo de missionários americanos e seus familiares. 0 primeiro surto, tido como sendo de hepatite viral em bases clínicas e alteração das aminotransferases e da bilirrubina, na ocasião foi considerado como não B e posteriormente, pela conservação adequada dos 
soros dos pacientes e seus comunicantes, com advento dos reagentes para os marcadores do vírus da hepatite A, ficou estabelecido 0 diagnóstico como um surto desses vírus . 0 segundo surto, com os primeiros casos ocorrendo dois a três meses depois do primeiro foi diagnosticado como causado pelo HBV. A investigação epidemiológica estabeleceu a causalidade ${ }^{9}$, 0 de hepatite A por uma falha do sistema de tratamento da água e o pelo HBV por aplicação de imunoglobulina contaminada com esse vírus.

Com 0 objetivo de contribuir para um maior esclarecimento dos aspectosclínicos, epidemiológicose histopatológicos da febre negra, Barberino Santos, orientado por A. Prata, realiza vigilância dessa nosologia, no município de Lábrea, de agosto de 1973 a dezembro de 1975. Neste período identifica clinicamente nove casos dos quais de sete obteve amostras do fígado. Apesar do cuidadoso levantamento das condições clínicas observadas durante 26 meses a ajuda laboratorial foi escassa, motivando 0 autor a anotar: A existência de formas benignas na região não pode ser afirmada com base nos achados clínicos, unicamente ${ }^{28}$.

A experiência bem sucedida de Altamira, a constatação que 0 sistema de expedições temporárias não acrescentava mais informações além das que já se dispunha, motivaram Bensabath e Pinheiro a proporem a várias financiadoras projetos de pesquisas sobre a febre negra de Lábrea. Os projetos tinham como objetivo geral desenvolver pesquisas contínuas e definidas sobre essa nosologia, procurando esclarecer sua etiologia e fatores coadjuvantes, prevalência e incidência,e informações clínicas apoiadas em dados laboratoriais e previam uma atuação multidisciplinar. Com este intuito foram incluídos também os seguintes pesquisadores do IEC: Amélia H.P.Andrade( arbovírus), Zéa C.Lins ( Bacteriologia), Mario A.P. Moraes (Histopatologia), Habib Fraiha Neto (Parasitologia). Como colaboradores, o professor Aluizio Prata, assessor da Secretaria de Saúde do Estado do Amazonas para os estudos da febre negra de Lábrea e Heitor Dourado professor da Universidade Federal do Amazonas. 0 projeto previa uma área sentinela (a sede do município de Lábrea) e transporte próprios terrestre e fluvial.

\section{5 -1988: IMPLANTAÇÃO DAS ÁREAS SENTINELAS DO RIO PURUS E A SOROLOGIA PARA OS VÍRUS DA HEPATITE A E D}

Com a instalação dos pólos agropecuários na Amazônia ( POLAMAZÔNIA) financiados pela Superintendência de Desenvolvimento da Amazônia (SUDAM) foi possível obter financiamento, em 1975, para um dos projetos, a esta altura com substanciais modificações: mudança de área sentinela e a inclusão de colaboradores somente do IEC.

Ainda neste ano, em novembro, foram iniciadas as atividades de campo, com a instalação de um posto de pesquisa do IECFSESP em Sena Madureira, Acre (Figuras 5 e 6 ) e que em fevereiro de 1979 foi transferido para Boca do Acre, (Figuras 7 e 8) Amazonas, onde permaneceu ininterruptamente até dezembro

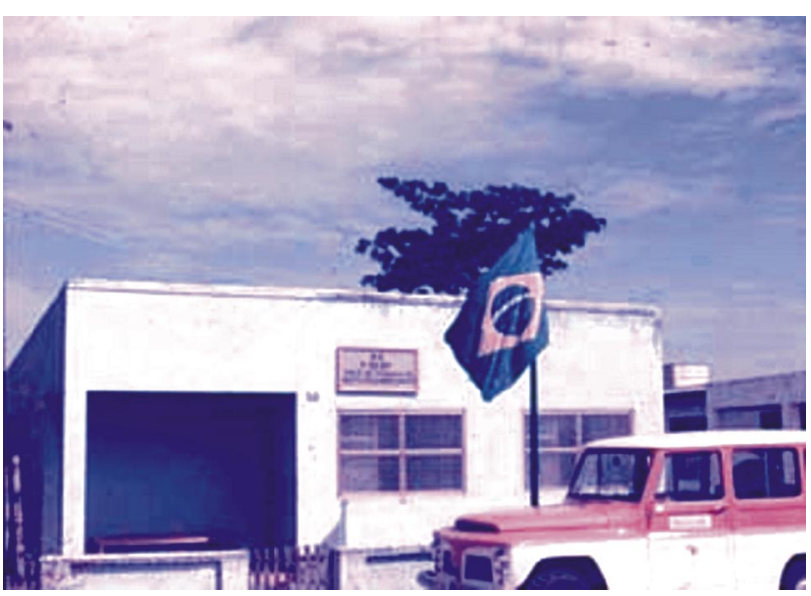

Figura 5 - Posto de pesquisa de campo em Sena Madureira, Acre.

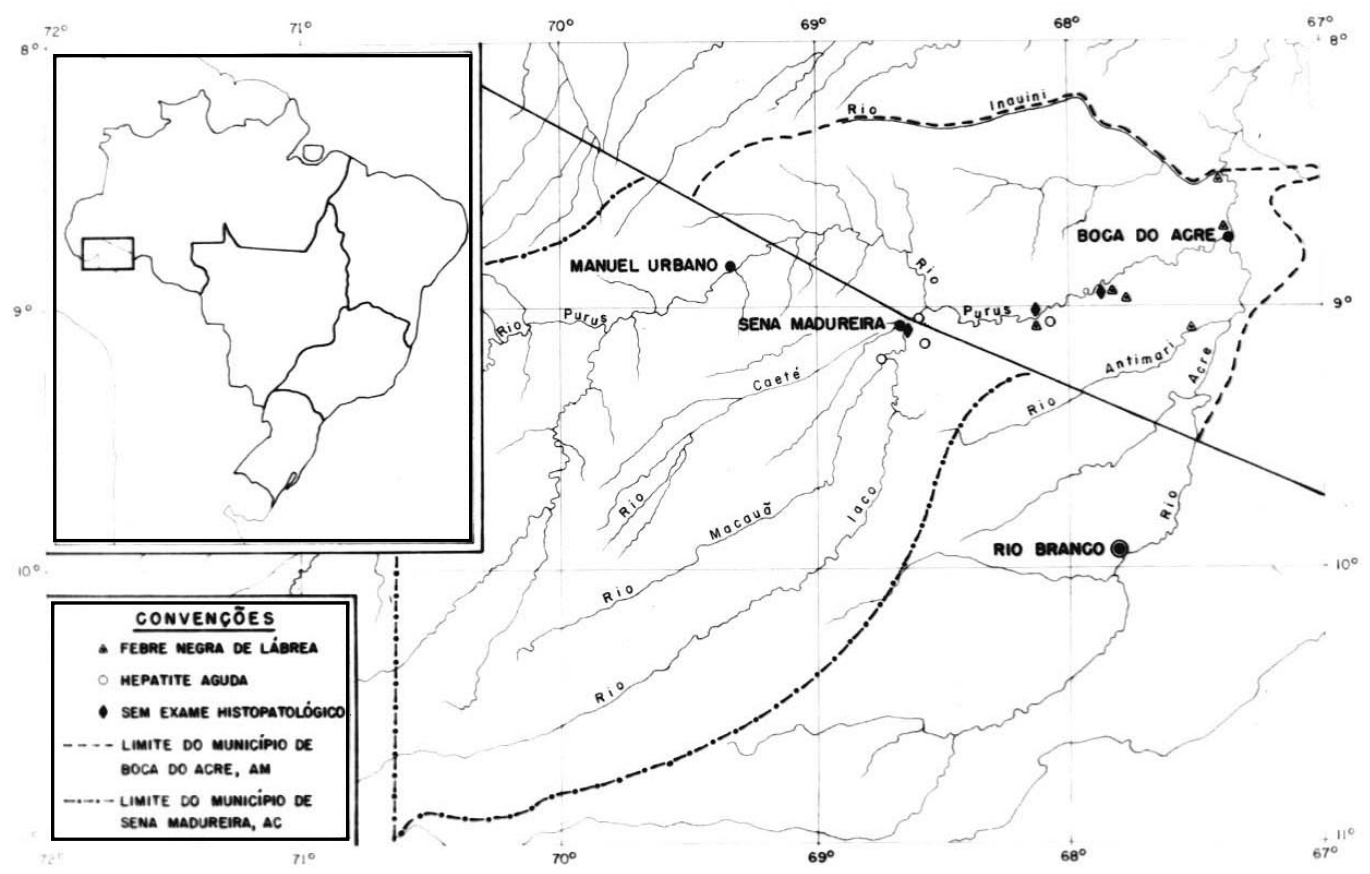

Figura 6 - Mapa com as localizações dos Postos sentinela para o estudo das hepatites virais nos municípios de Sena Madureira e Boca do Acre. 


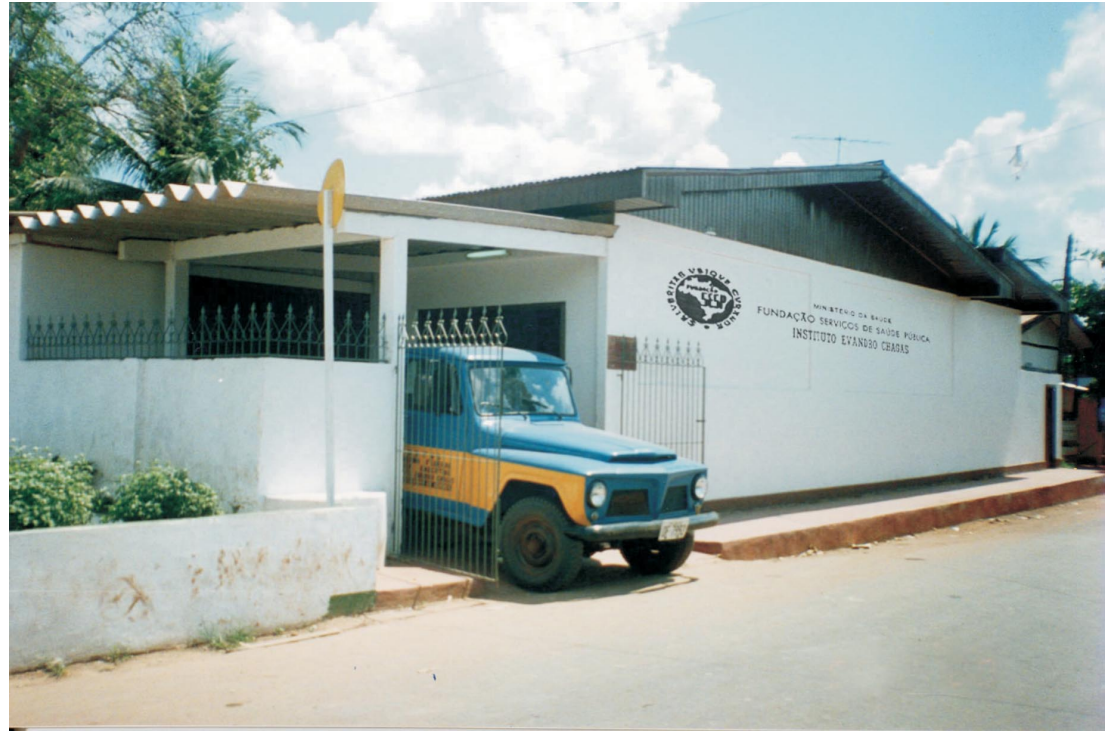

Figura 7 - Posto de pesquisa de campo em Boca do Acre, AM, de 1990 a 1994. Área externa.

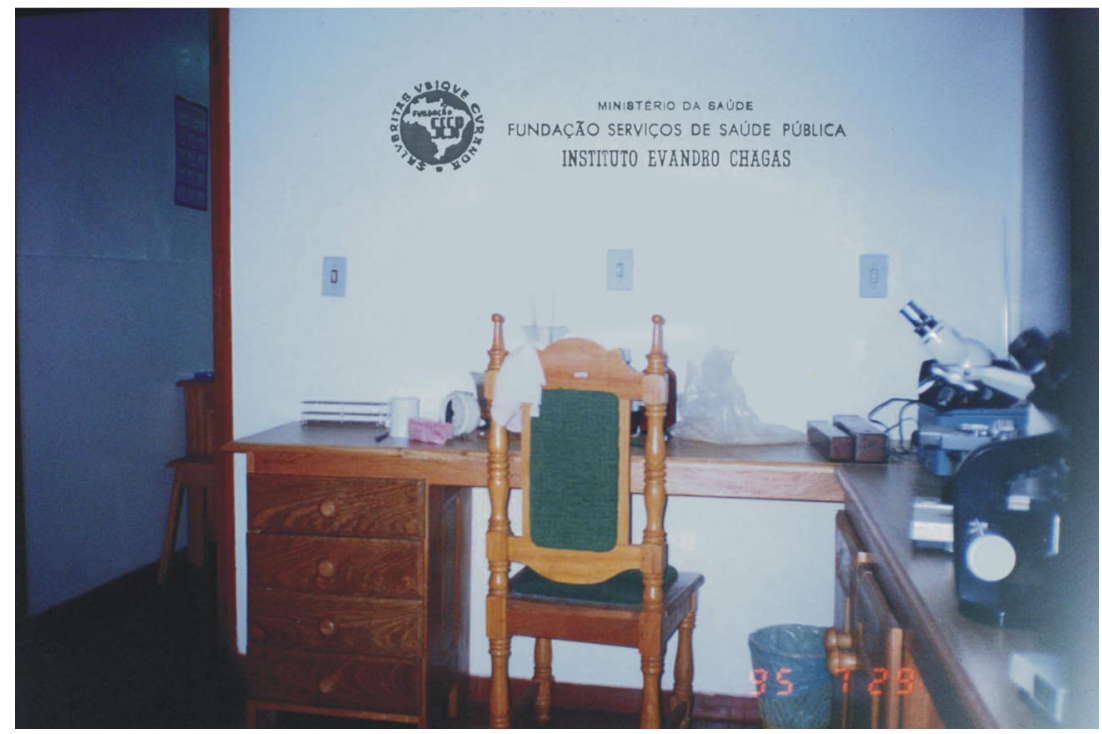

Figura 8 - Área interna do posto de pesquisa de campo em Boca do Acre, AM, de 1990 a 1994.

de 1994 dispondo de transporte próprio, fluvial nos cinco anos iniciais e terrestre por todo o período.

Nos seis primeiros anos, além da vigilância epidemiológica das síndromes ictéricas com a realização dos exames de Patologia Clínica no próprio local, foram realizados inquéritos soroepidemiológicos em assintomáticos, tanto da área urbana como rural. Na área urbana os assintomáticos foram selecionados por meio de sorteio de $10 \%$ das residências sendo examinados todos os moradores da residência sorteada com mais de seis meses de idade. Foi também iniciada de maneira sistematizada estudos multidisciplinares envolvendo a população humana e animais silvestres (vetores e reservatórios), para arbovírus.

A evolução do conhecimento e da tecnologia conseqüentemente e praticamente ao mesmo tempo, tornou disponível técnicas mais sensíveis, consideradas de terceira geração, sendo introduzida em 1976 a hemaglutinação passiva reversa, e em 1981 a detecção do HBsAg e posteriormente os demais marcadores do HBV ( 1983 e 1984) e os do vírus da hepatite A (HAV) pelos ensaios imunoenzimáticos. Utilizando ainda a técnica de hemaglutinação foi encontrada em uma amostra da população de Sena Madureira uma das mais altas prevalências do HBsAg em indivíduos assintomáticos no Brasil (Tabela 2).

Os testes sorológicos, quer para diagnóstico etiológico, quer para estudos de soroprevalência foram realizados nos laboratórios do IEC em Belém, ou no CDC em Atlanta, Estados Unidos (coletas até 1985). Os testes realizados em Belém tiveram substancial auxílio técnicos de Olglaíze do Socorro da Costa Souza, Elizabete Maria de Figueiredo Brito e Maria Auxiliadora Barra.

Neste período, os estudos realizados nesta área forneceram as seguintes informações:

- as infecções pelo HAV e HBV são altamente endêmicas em ambos os municípios. Em Boca do Acre a morbidade específica é de 333 casos por $10^{5}$ habitantes/ano que é cerca 
de três vezes o observado para outras partes da Amazônia e com 0 coeficiente de mortalidade, também especíico de $32,5 / 10^{5}$ habitantes/ano $0^{4}$. Para a hepatite B, isolado ou associado ao delta 0 coeficiente de morbidade foi de $154 / 10^{5}$ habitantes/ano com uma letalidade de $12,7 \%^{8}$. Tanto pelo HAV como pelo HBV a maioria das infecções ocorrem antes dos 14 anos de idade;

- a detecção pela primeira vez do vírus da hepatite Delta (HDV) na microregião de Purus, em pacientes com as formas fulminantes (febre negra de Lábrea), em hepatite aguda com recuperação, crônicos e em assintomáticos ${ }^{1}$;

- esclarecimento da etiologia da febre negra de Lábrea ( hepatite de Lábrea, como principalmente uma superinfecção ou coinfecção pelo delta, podendo contudo em menor proporção haver outras ( Figura 9).

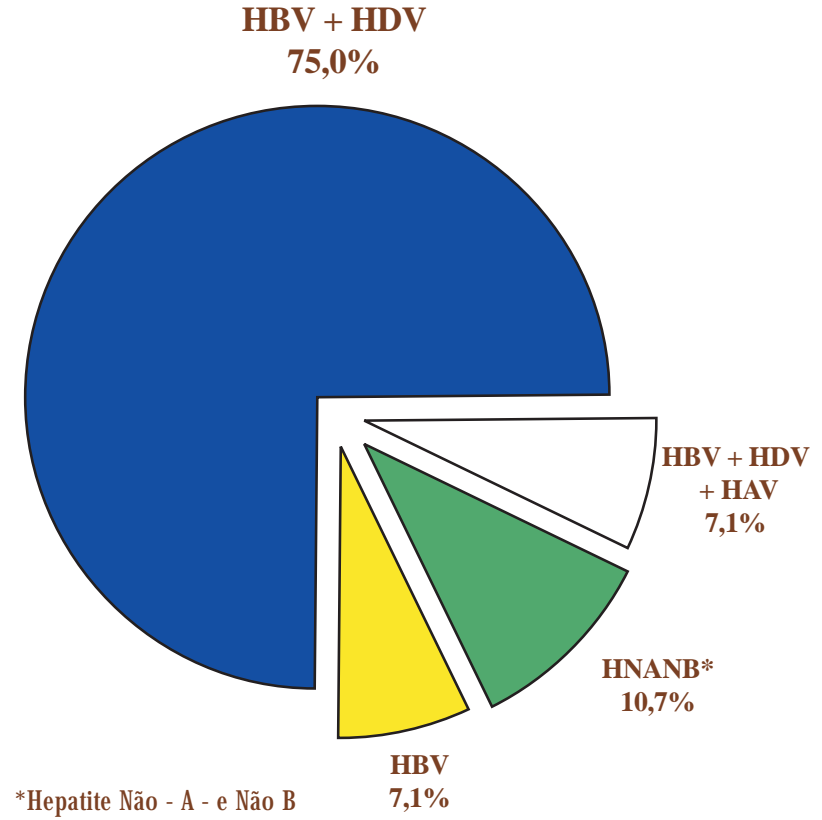

Figura 9 - Etiologia da hepatite fulminante em 32 casos de Boca do Acre, AM, Brasil.

- a associação com o HDV foi também estudada por outros autores, cabendo a Fonseca et al assinalar pela primeira vez a presença de antígeno no fígado em pacientes do Baixo Solimões ${ }^{19}$.

- foi verificado a incidência de casos de hepatite A em portador do HBV e HDV com apenas um dos 16 observados com evolução para a fase encefálica e com recuperação.

A prevalência do HDV em assintomáticos portadores do HBsAg, foi estudado, em 99 pessoas, das quais 57 residiam na área urbana e 42 na rural, com menos de um a mais de 40 de idade. A proporção de prevalência está correlacionada com a idade tendo sido negativa 20 crianças examinadas com menos de 5 anos de idade 5 .

Como estes estudos e de outros autores ${ }^{17}{ }^{18}{ }^{19}$ demonstraram que, inegavelmente, $0 \mathrm{HBV}$ estava relacionado com o desencadeamento das formas fulminantes das hepatites virais na Amazônia e, como já existia uma vacina segura e eficaz contra esse vírus especialistas reunidos em Manaus em dezembro de 1986, no Primeiro Simpósio Brasileiro sobre Delta, sugeriram a vacinação ser estendida aos 13 municípios (entre os quais Boca do Acre) para os já havia informação suficiente sobre a alta endemicidade do HBV e HDV. Caberia ao Ministério da Saúde, a escolha da vacina.

A fase de planejamento para Boca do Acre, foi realizado no IEC e encaminhada em 1987 a FINEP. Os recursos financeiros solicitados a FINEP só foram liberados em 1989 e insuficientes, sendo necessário a execução de vários projetos adicionais inclusive pelo próprio Ministério da Saúde (Secretaria Nacional de Ações Básicas de saúde, SNABS), a quem coube a coordenação a nível nacional.

Outro problema que originou a protelação foi a indefinição da escolha da vacina, só resolvido com a decisão do MS iniciar 0 controle da hepatite B no Brasil. Foram então tomadas medidas que tornariam possível definir parâmetros, não só para a escolha da vacina, doses, intervalos de aplicação. Entre estas medidas constava a implantação de uma comissão consultiva de hepatites virais com dois representantes da Amazônia.

\section{9 - 1994: OPERACIONALIZACÃO DA VACINA CONTRA HEPATITE B EM MASSA, IMPLANTAÇÃO DAS VACINAS NO PROGRAMA NACIONAL DE IMUNIZACÕES. ESTUDOS DE IMUNOGENCIDADE ESEGURANÇANESSASDUAS LOGÍSTICAS}

Com adoção pelo Ministério da Saúde do plano prioritário para o controle da hepatite B no Brasil, que tinha entre outros objetivos, vacinar todas as crianças menores de 10 anos de idade, residentes na Amazônia Ocidental, a primeira fase seria iniciada naqueles 13 municípios recomendados pelos especialistas do Primeiro Simpósio sobre Delta de Manaus em 1986.

Por motivos operacionais e técnicos foram elaborados dois projetos cada qual com sua coordenadoria, cabendo ao responsável pela SNABS, Drs. Edmundo Juarez depois Presidente da FSESP e Claudio Amaral, a coordenação geral. Estes projetos foram os seguintes:

1. Vacinação contra hepatite $B$, em municípios hiperendêmicos do Estado do Amazonas, abrangendo as áreas urbanas e rurais de Canutama, Carauari, Coari, Codajas Eirunepé, Envira, Ipixuna, Itamarati, Lábrea, Pauini e Tapauá. O planejamento desteprojeto ficou a cargo de uma comissão multi-institucional constituída por técnicos das instituições de saúde, localizadas em Manaus e que eram as seguintes: Instituto de Medicina Tropical e Coordenadoria de Epidemiologia, ambos da Secretaria de Saúde do Estado do Amazonas, Superintendência de Campanhas de Saúde Pública ( SUCAM) e Diretoria Regional do Amazonas ( FSESP). Este grupo era chefiado e coordenado pelo pesquisador de hepatites virais do Instituto de Medicina Tropical do Amazonas, José Carlos da Fonseca.

2. Vacinação contra hepatite B em Boca do Acre, Amazonas. Estudos de sua imunogenicidade e eficácia. Este projeto foi planejado, administrado, parcialmente executado em suas atividades de campo e, totalmente nas atividades de laboratório pela equipe da Seção de Hepatopatias do IEC a cuja chefia também coube à coordenadoria deste projeto. 
A metodologia inclui dois aspectos:

\subsection{Vacinação propriamente dita}

2.2. Estudos da duração da imunogenicidade e da eficácia da vacina.

A meta seria vacinar $80 \%$ das 7.724 crianças de 0 a 9 anos residentes no município de Boca do Acre (estimativa da Secretaria de Saúde do Amazonas). As que fossem nascendo após a aplicação da $2^{\underline{a}}$ dose receberiam a vacina contra a hepatite $B$ junto com as vacinas do Programa Nacional de Imunizações. Também seriam vacinados os profissionais de saúde imigrantes que estivessem trabalhando nas instituições públicas e privadas do município.

Os estudos de eficácia seriam realizados com a continuação da vigilância das síndromes ictéricas e, os da imunogenicidade em $20 \%$ dos suscetíveis diagnosticados pela sorologia pré-vacinal, durante um período de 3 anos.

Estes aspectos foram desenvolvidos em 4 etapas, cada qual com a sua problemática: 1) Preparatória, 2) Execução, 3) Apuração de resultados e análises e 4) Divulgação. Neste trabalho nos reportaremos somente as atividades desenvolvidas em Boca do Acre.

Etapa preparatória. Para a obtenção dos objetivos mencionados nos projetos, impunha-se participação multiinstitucional não só da área de saúde como lideres comunitários. Para isto foram mantidos contatos com autoridades desde Brasília até Boca do Acre, Secretário de Saúde do Amazonas, Diretores Regionais da FSESP, Prefeitura Municipal, presidente da Câmara dos Vereadores, Médicos e Líderes Locais.

Vacina. A vacina utilizada foi a produzida por tecnologia de DNA recombinante pelo laboratório Smithkline Biologicals Rixensart, Belgica, denominada Engerix B com a apresentação

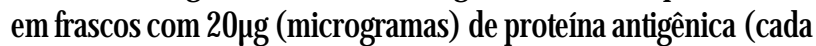
$0,5 \mathrm{ml}$ correspondendo a uma dose pediátrica de $10 \mathrm{mg}$ ) . Em agosto de 1989, foram enviados pelo Dr. Rodrigo Soares do PNI ( Rio de Janeiro), 23.000 doses que pertenciam ao lote 16 Eng-525 A 2 com data de fabricação de julho de 1988 e prazo de validade até 07.1990, doadas pelo Ministério da Saúde, juntamente com 16.000 seringas descartáveis de $1 \mathrm{ml}$. Destas vacinas, cerca de 5.200 doses foram usadas em profissionais de saúde no Pará e 2.000 doses nos profissionais do Estado do Acre.

Vacinação na área urbana. A primeira dose teve início dia 31.08.89 e terminou dia 20 de setembro seguinte, a segunda dose, no período de 2 a 26 de outubro do mesmo ano, com intervalo médio de 32 dias. A terceira dose teve início em março de 1990 e terminando em abril do mesmo ano.

Área rural terminou em dezembro de 1990. Dos

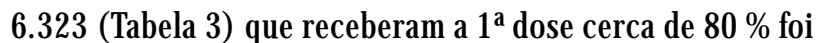
retirado uma amostra de soro para o perfil sorológico prévacinal, podendo estabelecer a taxa de conversão para as 3 doses que até um ano de idade foi de $100 \%$, de 2 a 4 anos de $96,1 \%$ e de 5 a 9 anos de $94,5 \%$.

A cobertura da vacina em relação as três doses foi na área urbana de $89 \%$ e na área rural $78 \%$ são expressivas para as difíceis condições existentes, e deve ser creditada ao longo convívio da equipe com a população.
Tabela 3 - Número de doses aplicadas segundo a área de residência.

\begin{tabular}{lrrr}
\hline Doses & Área urbana & Área rural & Total \\
\hline Dose 1 & 3106 & 3217 & 6323 \\
Dose 2 & 3039 & 3016 & 6055 \\
Dose 3 & 2774 & 2522 & 5296 \\
\hline
\end{tabular}

Inclusão no PNI. A vacina contra hepatite B como rotina do PNI foi iniciada a 14 de novembro de 1995, em uma criança de 4 dias de nascida que recebeu a $1 \stackrel{\text { a }}{ }$ dose simultaneamente com a BCG.

\section{CONCLUSÕES}

Considerando que novas e complexas tecnologias colocam ao dispor dos pesquisadores, os desafios a enfrentar não nos parecem menores que a longa trajetória ora descrita.

Como irão reagir os vírus submetidos a pressão da imunidade coletiva, se não houver contínua e sistematizadas atividades de pesquisa para 0 seu conhecimento?

Portanto, a tarefa não está concluída.

\section{AGRADECIMENTOS:}

Ao corpo técnico do Instituto Evandro Chagas que viabilizou as atividades relatadas neste trabalho. Agradecimento especial aos técnicos Guilherme Brígido Nunes, Lindomar de Souza Vasconcelos, Carlos Alberto Tenório da Silva e Bernardo Farias da Conceição.

\section{REFERÊNCIAS BIBLIOGRÁFICAS}

1. Bensabath G. Presença do agente delta associado a VHB em residentes do município de Boca do Acre, microregião do Purus, Amazonas. In: Anais do Congresso da Sociedade Brasileira de Medicina Tropical. Rio de Janeiro, p.150, 1983.

2. Bensabath G. Boshell JM. Presença do Antigeno Austrália (Au) em populações do interior do Estado do Amazonas-Brasil. Revista do Instituto de Medicina Tropical 15: 284-288, 1973.

3. Bensabath G, Dias LB. Hepatite de Lábrea (febre negra de Lábrea) e outras hepatites fulminantes, em Sena Madureira, Acre e Boca do Acre Amazonas, Brasil. Revista do Instituto de Medicina Tropical 25: 182-194, 1983.

4. Bensabath G, Hadler SC, Soares MCP, Fields H, Dias LB, Popper H, Maynard JE. Hepatitis delta vírus infection and Lábrea hepatites. Prevalence and role in fulminant hepatitis in the Amazon basin. Journal American Medical Association 258: 479-483, 1987.

5. Bensabath G, Hadler SC, Soares MCP, Fields H, Maynard JE. Epidemiologic and serologic studies of acute viral hepatites in Brazil's Amazon Basin. Pan American Health Organization Bulletin 21: 16-27, 1987.

6. Bensabath G, Maroja 0 Aspecto epidemiológico do antígeno de superfície do vírus da hepatite B em portadores sãos na Amazônia. In: Resumos do Congresso da Sociedade Brasileira de Hematologia e Hemoterapia p.4-6,1997.

7. Bensabath G, Soares MCP. A febre negra de Lábrea e infecções pelo vírus delta. In: Instituto Evandro Chagas ( org) 50 anos de contribuição às ciências biológicas e a Medicina Tropical. Fundação Serviços de Saúde Pública, Ministério da Saúde. Belém p. 531-581, 1986.

8. Bensabath G, Soares MCP. Hepatite B e Delta em Boca do Acre, alto Purus. Moderna Hepatologia 14: 36-40, 1989. 
9. Bensabath G, Soares MCP, Maia MMS. Hepatites por virus. In: Instituto Evandro Chagas ( org) 50 anos de contribuição às ciências biológicas e à Medicina Tropical. Fundação Serviços de Saúde Pública, Ministério da Saúde. Belém p. 483-529, 1986.

10. Blumberg BS, Gersthey BJS, Hungerford DA, London WT, Sutnick AI. A serum antígen (Australia antigen) in Down's syndrome leukaenia and hepatitis. Annals Internals Medical 66: 924, 1967.

11. Boshell JM. Estudos sobre a "febre negra" ou hepatoencefalopatia amazônica. Relatório interno . Instituto Evandro Chagas da Fundação Serviços de Saúde Pública. Belém p. 1970.

12. Costa EA. Febre negra do Rio Purus; algumas observações acerca de um surto na "Praia do Inferno" Boca do Acre - Amazonas. Gazeta Medica da Bahia 70: 148-175, 1970

13. Cruz OG. Relatório sobre as condições médico sanitárias do Valle do Amazonas, Rio de Janeiro, 1913. In: Daoci P (ed) Sobre o saneamento da Amazônia Manaus p. 72-82, 1972.

14. Dias LB, Costa EA, Pereira NG, Bensabath G. Colóquio sobre Febre Negra. In: Resumos do Congresso da Sociedade Brasileira de Medicina Tropical, Manaus, p.9, 1971.

15. Dias LB , Moraes MAP. Hepatite de Lábrea. Revista do Instituto de Medicina Tropical 15: 86-93, 1973

16. Dias LB, Pinheiro F. Hepatite no Território de Rondônia. Boletim Epidemiológico Fundação Serviços de Saúde Pública 4: 69-71, 1969.

17. Fay OH, Hadler SC, Maynard JE, Pinheiro F. La hepatitis en las Américas. Boletin Epidemiological Organization Panamericana Salud 6: 1-7, 1985.

18. Fonseca JCF, Ferreira LCL, Guerra ALPS, Passos LM, Simonetti JP. Hepatite fulminante e febre negra de Lábrea: estudo de cinco casos procedentes de Codajás, Amazonas, Brasil. Revista da Sociedade Brasileira de Medicina Tropical 16:144-147, 1983.
19. Fonseca JCF, Gayotto LCC, Ferreira LCL, Araujo JR Alecrim WD, Santos RTM, Simonetti JP, Alves VAF. Lábrea hepatitis - Hepatitis B and delta antigen expression on liver tissue: report of three autopsy cases, preliminary report. Revista do Instituto de Medicina Tropical de São Paulo 27: 224-227, 1985

20. Fonseca JCF, Simonetti SR, Tavares AM, Alencar MJ, Oliveira SS, Simonetti JP. Aspectos epidemiológicos da infecção pelo vírus da hepatite Delta (HDV) e portadores assintomáticos do vírus da hepatite B (HBV) no Estado do Amazonas - Brasil. Revista da Sociedade Brasileira de Medicina Tropical 19:120, 1986

21. Pinheiro ATP. Viver Amazônico. Instituto de Pesquisa e Estudo. 270 p, 2000.

22. Rockeller Foundation e Fundação Serviço Especial de Saúde Pública, Ministério da Saúde. Belém Vírus Laboratory. Annual Report p. 42-43, 1964.

23. Rockfeller Foundation e Fundação Serviço Especial de Saúde Pública, Ministério da Saúde. Belém vírus Laboratory. Annual Report, 1965.

24. Rockfeller Foundation e Fundação Serviço Especial de Saúde Pública, Ministério da saúde. Belém Vírus Laboratory. Annual Report, 1966.

25. Rockfeller Foundation e Fundação Serviço Especial de Saúde Pública, Ministério da Saúde. Belém Vírus Laboratory. Annual Report, 1967.

26. Rockfeller Foundation e Fundação Serviço Especial de Saúde Pública Ministério da Saúde. Belém Vírus Laboratory. Annual Report, 1968.

27. Rodrigues Filho A, Salles JM, Vianna CM, Leitão EG. Febre negra: considerações sobre aspectos clínicos. Revista da Universidade Federal do Pará, série II: 321-342, 1871

28. Santos JB. Febre negra de Lábrea (AM) : estudo clínico epidemiológico e histopatológico. Revista de Patologia Tropical, 12: 53-143. 1983.

29. Shope RE. An history of arbovirology in Brasil: Belém, PA 1954-1965. In: Rosa APAT, Vasconcelos PFC, Rosa JFST (eds) An overview of Arbovirology in Brasil and neigh bourina countries. Instituto Evandro Chagas. Belém p. 13-17, 1998. 